\title{
Analysis of Writing Materials in Middle Persian Documents
}

\author{
J. G. Barabe*, G. Azarpay**, K. A. Martin*, A. S. Teetsov* \\ * McCrone Associates, Inc., 850 Pasquinelli Drive, Westmont, IL 60559 \\ ** University of California, Berkeley
}

The Pahlavi Archive, currently housed at the University of California at Berkeley, is a collection of Middle Persian bullae and manuscripts, dating to the early post-Sasanian period in the seventh and eighth centuries. Although the writing surfaces were presented as being composed of leather or silk, none of the materials had been subjected to scientific testing to verify their nature. Figure 1A shows a leather document in the collection. Here, we describe the analysis of a random selection of document fragments using several micro-analytical techniques.

One of the document samples consisted of three fragments of stiff, warped, tan-colored material with ink markings on one face. Examination by light microscopy revealed the presence of hair fibers, indicating an animal origin for the document (Figure 1B). Comparison of hair fibers from the document fragment was made to fibers from a domestic U.S. goat, which were found to be very similar. Comparison was also made of collagen fiber bundles removed from the document fragment to collagen bundles from samples of modern sheep, calf and goat parchment [1]. Collagen bundles from goat parchment were found to be most similar to the collagen from the document (Figure 2). In addition, UV-fluorescence examination of the document fragment, as well as other tests, supported the identification of the material as parchment rather than leather [2]. Thus, this document material appears to be goat-based parchment.

The ink on the document fragment was examined by PLM, Raman spectroscopy and SEM-EDS, all of which support an identification of carbon ink rather than iron gall ink. Furthermore, the ink morphology was highly suggestive of a lamp black rather than a charcoal black pigment. A higher incidence of clay minerals in the ink compared to the underlying substrate suggests the possibility that the ink was manufactured or stored in a clay pot.

An initial analysis by infrared spectroscopy of five other document fragments found them to be cellulosic (plant-based) rather than silk, as had been expected. PLM examination identified three of these fragments to be composed of bast fibers, the most common of which are flax and hemp, and two of the fragments as cotton. The bast fiber fragments were all woven cloths in a 1:1 plain weave, with both fill and warp directions in a $\mathrm{Z}$ twist (Figure 3).

Accurate characterization of ancient materials is often of great importance as it can clear up misconceptions about the nature of these materials and can influence decisions regarding conservation and storage.

\section{References}

[1] Parchment samples were provided courtesy of the Newberry Library of Chicago, Illinois.

[2] R. Reed, Ancient Skins Parchments and Leathers, Seminar Press, London, 1972.

[3] Several colleagues who contributed to this work are gratefully acknowledged: Richard Bisbing, Kristen Skraba and Joseph Swider. 

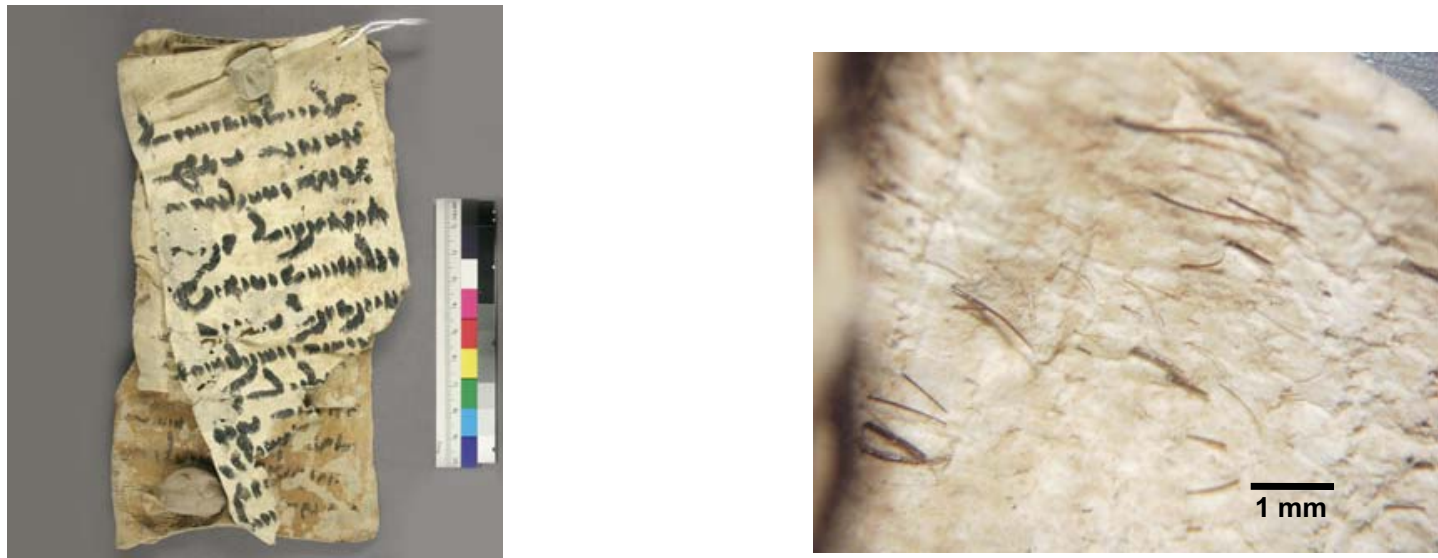

FIG. 1. Left: Leather document, courtesy of the Bancroft Library, University of California, Berkeley. Right: Fragment of a leather document showing animal hairs.
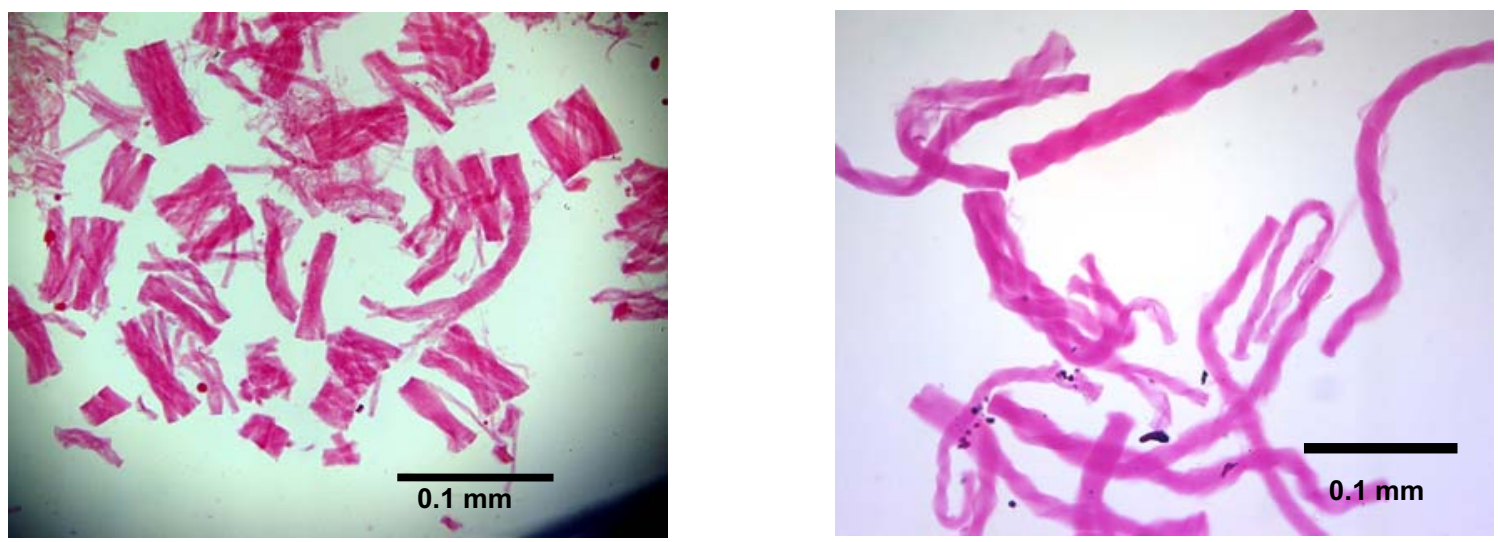

FIG. 2. Collagen bundles removed from document fragment (left) and modern goat parchment (right).
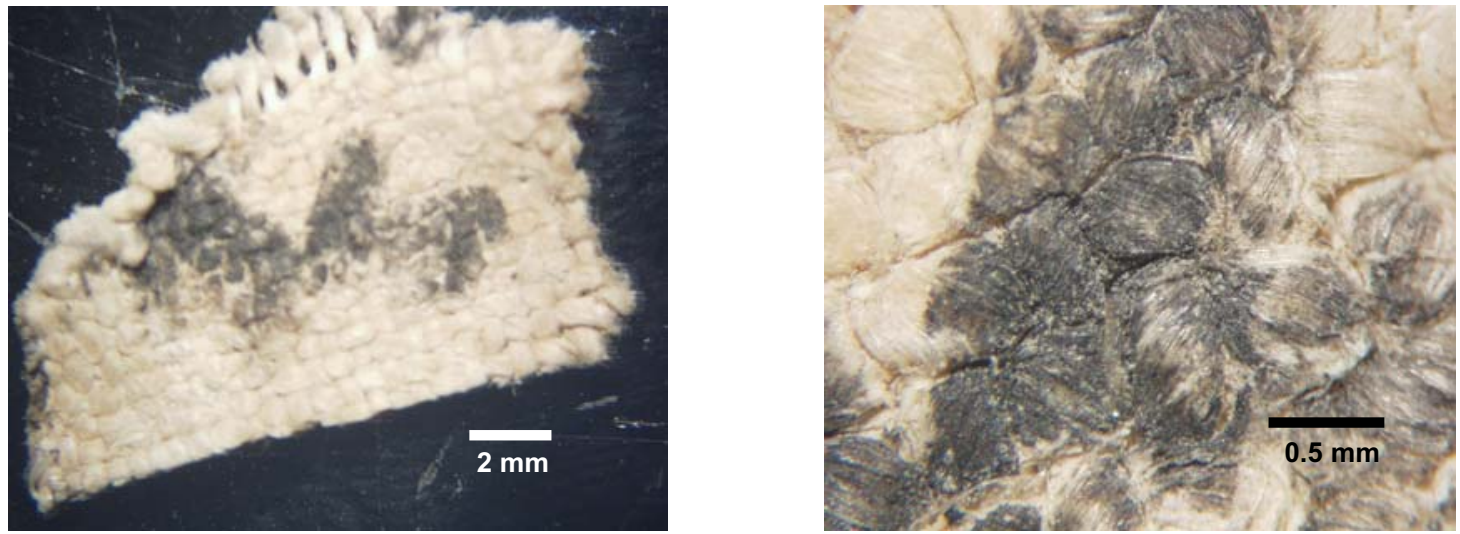

FIG. 3. Bast-fiber document fragment with ink markings. 